\title{
Diaphragm Mechanics in Dogs with Unilateral Emphysema
}

\author{
Rolf D. Hubmayr, Gaspar A. Farkas, Hung-Yang Tao, Gary C. Sieck, and Susan S. Margulies \\ Department of Internal Medicine, Division of Thoracic Diseases and Critical Care, and the Departments \\ of Anesthesia and Physiology \& Biophysics, Mayo Clinic and Foundation, Rochester, Minnesota 55905
}

\begin{abstract}
We studied dogs with unilateral papain-induced emphysema to answer two questions: (1) Do emphysema lung-apposed hemidiaphragm $\left(\mathrm{Di}_{\mathrm{E}}\right)$ and normal lung-apposed hemidiaphragm $\left(\mathrm{Di}_{\mathrm{N}}\right.$ ) have equal capacities for lowering lung surface pressure? and (2) Are side-to-side differences in intrathoracic pressure the result of unequal force outputs by $\mathrm{Di}_{\mathrm{E}}$ and $\mathrm{Di}_{\mathrm{N}}$ or are they caused by differences in their mechanical efficiency as pressure generators? After the airways of the emphysematous and normal lungs were intubated with a dual lumen endotracheal tube, both phrenic nerves were maximally stimulated at rates between 1 and $50 \mathrm{~Hz}$ and the changes in airway occlusion pressure $\left(\Delta \mathbf{P a o}_{\mathrm{E}, \mathrm{N}}\right)$ and diaphragm length (sonomicrometry) were recorded. In all animals, $\Delta \mathrm{Pao}_{\mathrm{N}}$ exceeded $\Delta \mathrm{PaO}_{\mathrm{E}}$. Differences in pressure ranged from $1.2 \pm 0.6 \mathrm{~cm} \mathrm{H}_{2} \mathrm{O}$ during a twitch to $6.0 \pm 2.9 \mathrm{~cm} \mathrm{H} \mathrm{H}_{2} \mathrm{O}$ during a $50-\mathrm{Hz}$ tetanus. Midcostal bundles of $\mathrm{Di}_{\mathrm{E}}$ shortened less than corresponding bundles of $\mathrm{Di}_{\mathrm{N}}$, but both reached the same active length relative to their optimal lengths, which were measured in vitro. There was no significant difference in fiber type distribution, fiber cross-sectional area, or maximal isometric tetanic tensions among midcostal regions of $D i_{E}$ and $D i_{N}$. We conclude that unilateral hyperinflation impairs the mechanical efficiency of the apposing hemidiaphragm as a pressure generator. (J. Clin. Invest. 1993.91:1598-1603.) Key words: regional ventilation $\bullet$ unilateral hyperinflation $\bullet$ single lung transplantation • chest wall mechanics
\end{abstract}

\section{Introduction}

Motivated by the introduction of single lung transplantation for the treatment of end-stage emphysema, we evaluated the effects of chronic unilateral hyperinflation on the mechanics of the canine diaphragm. Because the mechanical efficiency of the diaphragm is extremely sensitive to changes in lung volume (1), we reasoned that differences in length and shape between right and left hemidiaphragms may alter their respective functions. The first objective of this study was to test the hypothesis that chronic unilateral hyperinflation caused by emphysema alters the pressure-generating capacity of the emphysema lungapposed hemidiaphragm $\left(\mathrm{Di}_{\mathrm{E}}\right)^{1}$ relative to that of the normal

Address reprint requests to R. D. Hubmayr, Mayo Clinic, 200 First Street SW, Rochester, MN 55905.

Received for publication 15 June 1992 and in revised form 19 October 1992.

1. Abbreviations used in this paper: $\mathrm{Di}_{\mathrm{E}}$ and $\mathrm{Di}_{\mathrm{N}}$, emphysema and normal lung-apposed hemidiaphragm, respectively; Lo and Lr, optimal and resting lengths, respectively; Pao, airway occlusion pressure; TLC, total lung capacity; V, volume; Vrel, relaxation volume.

The Journal of Clinical Investigation, Inc.

Volume 91, April 1993, 1598-1603 lung-apposed hemidiaphragm $\left(\mathrm{Di}_{\mathrm{N}}\right)$. Our results in five dogs with unilateral experimental emphysema support this hypothesis. The second objective was to distinguish between two mechanisms, each of which could by itself explain the inequality in hemithoracic pressure during diaphragm activity: (1) $\mathrm{Di}_{\mathrm{E}}$ and $\mathrm{Di}_{\mathrm{N}}$ produce unequal forces because of differences in precontraction length (preload), contractile properties, and afterload; (2) $\mathrm{Di}_{\mathrm{E}}$ and $\mathrm{Di}_{\mathrm{N}}$ have unequal mechanical efficiencies in lowering thoracic pressure despite equal force generation. To answer this question, we compared the histochemical profile, the cross-sectional area of diaphragm muscle fibers, the in vitro contractile properties (length/tension and force/frequency relationships), and the in situ lengths of midcostal regions of $\mathrm{Di}_{E}$ and $\mathrm{Di}_{\mathrm{N}}$ in the original group of five animals and in five additional dogs.

\section{Methods}

Experimental emphysema. Right $(n=2)$ or left $(n=8)$ emphysema was induced by repeated endotracheal instillation of papain in 10 dogs $(10-35 \mathrm{~kg})$ as follows $(2,3)$. The dogs were anesthetized with pentobarbital sodium $(25 \mathrm{mg} / \mathrm{kg})$ and intubated with a dual lumen endotracheal tube. After patency of all lobar bronchi was endoscopically verified, the animals were placed in the lateral decubitus posture. A mixture of $4 \mathrm{ml}(25 \mathrm{mg} / \mathrm{ml}$ ) of papain solution (type III; Sigma Chemical Co., St. Louis, MO) diluted in $40 \mathrm{ml}$ of sterile normal saline was injected through a PE-200 catheter into the airways of the dependent lung. After the instillation, the dogs were mechanically ventilated for 6 $\mathrm{h}$ ( tidal volume $=15 \mathrm{ml} / \mathrm{kg}$, fractional $\mathrm{O}_{2}$ concentration $=0.6$ ). Penicillin and gentamicin were administered every $12 \mathrm{~h}$ for a total of four doses to prevent bacterial infection. The instillation procedure was repeated at approximately weekly intervals, resulting in four to seven treatments per animal. The experiments reported here were conducted 4-6 mo after the last enzyme treatment.

In situ mechanics measurements. The animals were lightly anesthetized with pentobarbital sodium $(25 \mathrm{mg} / \mathrm{kg})$. Five of them with right $(n=2)$ or left $(n=3)$ emphysema were intubated with a dual lumen endotracheal tube (Kottmaier; Willy Rüsch, Rommelshauser, Bei Stuttgart, Germany) and studied in the supine posture. The position of the endotracheal tube was adjusted to assure patency of all lobar bronchi. Airway pressures of the emphysematous $\left(\mathrm{PaO}_{\mathrm{E}}\right)$ and nonemphysematous lung $\left(\mathrm{PaO}_{\mathrm{N}}\right)$ were recorded from the oral ends of the respective endotracheal tube lumina. Gas flow to each lung was measured with separate pneumotachographs (2; Fleisch, OEM Medical Co., Richmond, VA) and differential pressure transducers (MP 45; Validyne Engineering Corp., Northridge, CA). Pressure and flow signals were displayed on a strip chart recorder (model 7758A; Hewlett Packard Co., Palo Alto, CA), as well as digitized and stored on a computer (11/73; Digital Equipment Corp., Marlboro, MA). Volume changes of the emphysematous and nonemphysematous lung $\left(\Delta V_{E}, \Delta V_{N}\right)$ were measuren hy computer integration of the digitized flow signals. The relaxation volume of each lung $\left(\mathrm{Vrel}_{\mathrm{E}}, \mathrm{Vrel}_{\mathrm{N}}\right)$ was measured after hyperventilation-induced apnea with a nitrogen equilibration technique (2).

In situ diaphragm length measurement and electrophysiologic techniques. The in situ resting lengths of $\mathrm{Di}_{\mathrm{E}}$ and $\mathrm{Di}_{\mathrm{N}}$ were measured with sonomicrometry in all 10 dogs $(4,5)$. After a midline laparotomy, pairs 
of piezoelectric crystals were embedded between the fibers of a mid costal muscle bundle in each hemidiaphragm.

In five dogs, hook electrodes were placed into the superficial muscle layers of $\mathrm{Di}_{E}$ and $\mathrm{Di}_{N}$; from these electrodes, compound muscle action potentials (CMAP) were recorded with an electromyographic instrument (TE 42; Teca Corp., Pleasantville, NY). Recording wires were exteriorized through the lateral abdominal wall, the abdomen closed, and residual air evacuated through a large-bore catheter. The spinal roots of the phrenic nerves were identified and isolated on both sides of the neck. Insulated hook electrodes were then placed around the nerve roots and the preparation was covered with mineral oil. Synchronous twitch stimulations (pulse duration of $0.2 \mathrm{~ms}$ ) were applied to the nerve roots using a dual nerve stimulator (S 88; Grass Instrument Co., Quincy, MA) to establish supramaximal stimulation conditions. In all five dogs, compound muscle action potential (CMAP) amplitudes reached a maximum at stimulation intensities below $30 \mathrm{~V}$.

Experimental protocol (in situ, $n=5$ ). During hyperventilation-induced apnea, the lungs were inflated with a calibrated supersyringe to a common airway pressure of $30 \mathrm{~cm} \mathrm{H}_{2} \mathrm{O}$. The thoracic gas volume at that pressure defined total lung capacity (TLC). The lungs were emptied in small-volume steps from TLC to residual volume (RV, Pao $\leq-30 \mathrm{~cm} \mathrm{H}_{2} \mathrm{O}$ ). These maneuvers were performed in triplicate and helped to delineate the relationships between hemidiaphragm lengths and the apposing lung volumes during relaxation. Thereafter, each lumen of the Kottmaier tube was occluded at Vrel as right, left, or both phrenic nerves were stimulated at frequencies between 1 and $50 \mathrm{~Hz}$. Changes in airway occlusion pressure $\left(\triangle \mathrm{PaO}_{\mathrm{E}}, \Delta \mathrm{PaO}_{\mathrm{N}}\right)$ and diaphragm lengths were recorded. The same stimulation sequence was repeated after establishing a communication between right and left endotracheal tube lumen through a $Y$ piece, while occluding the common port of the $Y$ to keep overall thoracic gas volume constant at Vrel. In this configuration, the two pneumotachographs were arranged in series, providing measurements of redistributed gas volume between the lungs (Pendelluft) from their average outputs.

Measurement of optimal length and contractile properties $(n=10)$. The techniques with which optimum lengths (Lo), maximal force, force-frequency curves, and length-tension properties of excised diaphragm strips were measured have been detailed by Farkas et al. (4). Briefly, in 10 animals costal diaphragm strips containing the sonomicrometer crystals were excised and immersed in cooled $\left(4^{\circ} \mathrm{C}\right)$ oxygenated Krebs solution. 5-8-mm-wide strips were mounted between platinum electrodes and placed in a muscle bath containing Krebs solution $\left(95 \% \mathrm{O}_{2}, 5 \% \mathrm{CO}_{2}, 37^{\circ} \mathrm{C}\right)$. Lo was defined as the length (determined by sonomicrometry) at which peak tension was recorded. These in vitro measurements provided the means to express in situ lengths of $\mathrm{Di}_{E}$ and $\mathrm{Di}_{\mathrm{N}}$ as percent Lo. Additional segments not containing the piezoelectric crystals were excised, mounted in a muscle bath, and allowed to thermoequilibrate for $15 \mathrm{~min}$, after which Lo was measured in triplicate with a micrometer. Force-frequency curves were evaluated at Lo and tetanic length-tension curves were measured at lengths between 50 and $125 \%$ Lo. Thereafter, the muscle segment was blotted dry and weighed and its cross-sectional area calculated from mass, length, and specific gravity (6).

Diaphragm muscle fiber morphometry and histochemistry ( $n$ $=10$ ). In 10 animals, including those in which in situ diaphragm function had been measured, strips from ventral and mid costal regions of each hemidiaphragm were excised and frozen at Lo with isopentane cooled to its melting point by liquid nitrogen. Serial transverse sections of $6-10-\mu \mathrm{m}$ thickness were cut with a cryostat held at $-20^{\circ} \mathrm{C}$. Muscle fibers were classified as type I or II based on their staining for myofibrillar adenosine triphosphatase (ATPase) after alkaline preincubation ( 7 , 8 ). Type II fibers were further classified as IIa, IIb, and IIc based on the pH lability of ATPase staining $(9,10)$. Between 100 and 200 fibers per specimen were sampled to estimate the fiber type proportions in $\mathrm{Di}_{\mathrm{E}}$ and $\mathrm{Di}_{\mathrm{N}}$.

The procedures for quantifying muscle fiber cross-sectional area have been described previously $(7,8)$. Muscle sections were magnified with a microscope (BH2; Olympus Corporation of America, New Hyde Park, NY) and digitized into a 1,024 × 1,024 array of picture elements (pixels) using a computer-based image processing system (1024XM; Megavision Corp., Goleta, CA). The image processing system was calibrated for morphometry with a microscope stage micrometer. Using a $\times 20$ objective, the area of each pixel was $0.15 \mu \mathrm{m}^{2}$. From the digitized images, the boundaries of 50 to 100 type I and type II fibers each were outlined. Fiber size was then computed from the number of pixels within the delineated fiber boundaries.

Data analysis. Unless indicated otherwise, measurements are presented as group means \pm standard error. Differences between the specific properties of $\mathrm{Di}_{\mathrm{E}}$ and $\mathrm{Di}_{\mathrm{N}}$ were analyzed with $t$ tests for paired observations after averaging the results of repeated measurements in each dog. Because no data set was submitted to more than one statistical comparison, a probability of $\leq 0.05$ on a two-tailed test was considered significant.

\section{Results}

Effect of lung volume on passive regional diaphragm length ( $n$ $=5$ ). Unilateral papain treatment resulted in an increase in thoracic TLC to $139 \pm 10 \%$ baseline. System Vrel increased from $40 \pm 5$ to $54 \pm 5 \%$ of baseline TLC. Vrel $_{\mathrm{E}}$ was $2.7 \pm 1.2$ times $\mathrm{Vrel}_{\mathrm{N}}$. Fig. 1 shows the passive lengths of $\mathrm{Di}_{\mathrm{E}}$ and $\mathrm{Di}_{\mathrm{N}}$ between TLC and RV in the five dogs in which intrathoracic pressure measurements during phrenic stimulation were subsequently made. Lung volume on the abscissa is expressed as percentage of baseline TLC, i.e., the intrathoracic gas volume at a Pao of $30 \mathrm{~cm} \mathrm{H}_{2} \mathrm{O}$ before the induction of emphysema. Hemidiaphragm lengths on the ordinate are expressed as a percentage of their lengths at Vrel ( $\mathrm{Lr}$ ), i.e., the relaxation volume of the respiratory system after the induction of emphysema. The broken line through open symbols represents the relationship for $\mathrm{Di}_{\mathrm{E}}$ (emphysema side), the solid line through closed symbols that for $\mathrm{Di}_{\mathrm{N}}$ (control side). Vertical bars indicate standard errors about the mean lengths. During a positive pressure inflation from Vrel, initially $\mathrm{Di}_{\mathrm{E}}$ and $\mathrm{Di}_{\mathrm{N}}$ shortened by similar amounts and reached a length of $89 \pm 4 \% \mathrm{Lr}$ near baseline TLC. A further increase in volume had no effect on the length of $\mathrm{Di}_{\mathbf{E}}$, while the length of $\mathrm{Di}_{\mathrm{N}}$ declined further to $74 \pm 3 \% \mathrm{Lr}$.

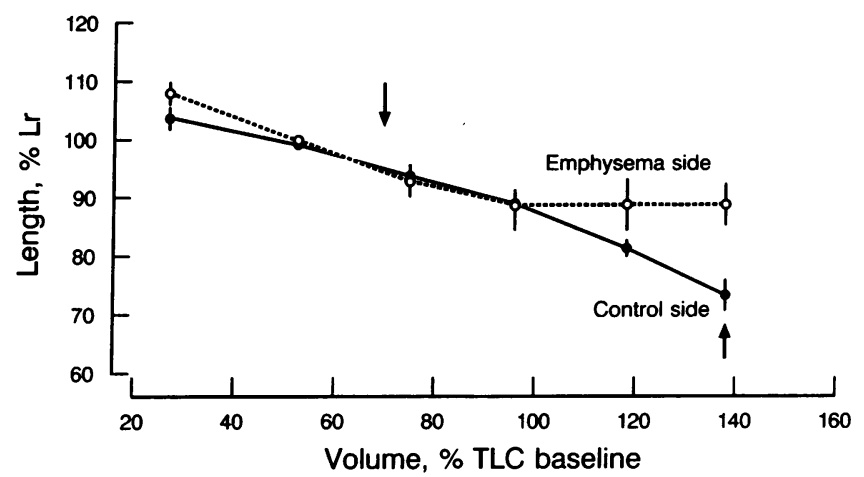

Figure 1. Effect of thoracic volume on passive lengths of $\mathrm{Di}_{\mathrm{E}}(\mathrm{em}-$ physema side) and $\mathrm{Di}_{\mathrm{N}}$ (control side) obtained in 5 dogs. Thoracic volume is expressed as percent total lung capacity (TLC) before the induction of unilateral emphysema (baseline). Passive lengths are expressed as \%Lr, i.e., the lengths of $\mathrm{Di}_{E}$ and $\mathrm{Di}_{\mathrm{N}}$ at Vrel after the induction of unilateral emphysema. The broken line through open symbols shows the relationship for $\mathrm{Di}_{\mathrm{E}}$ and the solid line through closed symbols that for $\mathrm{Di}_{\mathrm{N}}$. The arrows indicate the overall thoracic volume at which emphysematous (downward arrow) and nonemphysematous lungs (upward arrows) reached their respective baseline TLC volumes. 


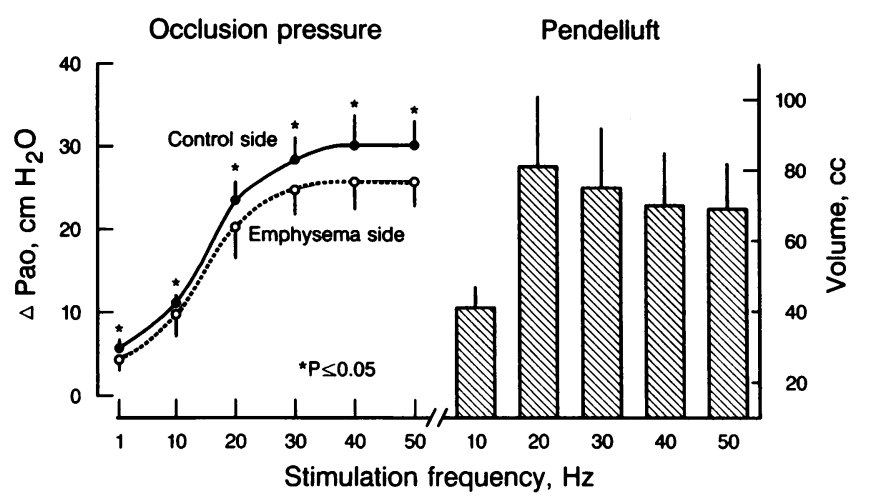

Figure 2. The left side shows the relationships between stimulation frequency in $\mathrm{Hz}$ (abscissa) and the airway occlusion pressure changes in emphysematous (broken line through open symbols) and normal (control side, solid line through closed symbols) lungs during bilateral phrenic nerve stimulations at $\operatorname{Vrel}(n=5)$. The right side shows the redistributed volumes after alveolar pressures were allowed to equilibrate during bilateral phrenic nerve stimulations at Vrel.

In situ pressure-generating capacity $(n=5)$. Fig. 2 (left $)$ shows the mean Pao values of five dogs during bilateral phrenic nerve stimulation at frequencies between 1 and $50 \mathrm{~Hz}$. Both ports of the divided airway had been occluded to prevent equalization of alveolar pressures and a redistribution of gas between the lungs. The broken line through open symbols represents the behavior of the emphysematous lung and the solid line through closed symbols that of the nonemphysematous, normal lung. In all five animals at all stimulation frequencies there was a significantly greater $\Delta \mathrm{Pao}$ within the normal lung than within the emphysematous lung. Differences between $\triangle \mathrm{PaO}_{\mathrm{N}}$ and $\triangle \mathrm{PaO}_{\mathrm{E}}$ ranged from $1.2 \pm 0.6 \mathrm{~cm} \mathrm{H}_{2} \mathrm{O}$ during a twitch $(26 \%$ difference, $P \leq 0.05$ ) to $6.0 \pm 2.9 \mathrm{~cm} \mathrm{H}_{2} \mathrm{O}$ during a $50-\mathrm{Hz}$ tetanus ( $15 \%$ difference, $P \leq 0.05$ ).

When alveolar pressures were allowed to equilibrate between the lungs, there was a redistribution of gas from the emphysematous to the nonemphysematous lung. Fig. 2 (right) shows the mean and standard errors of the redistributed gas volumes during stimulations between 10 and $50 \mathrm{~Hz}$. On average, during a fused tetanus $(20-50 \mathrm{~Hz})$, Pendelluft amounted to $18 \pm 16 \%$ of $\operatorname{Vrel}_{\mathrm{N}}(P \leq 0.05)$.

Morphometry, histochemistry, and contractile properties of regions from $D i_{E}$ and $D i_{N}(n=10)$. Table I lists individual and group mean values of fiber type distributions, their average cross-sectional area, and the maximal isometric tensions of $\mathrm{Di}_{\mathrm{E}}$ and $\mathrm{Di}_{\mathrm{N}}$ muscle strips. Accordingly, the canine diaphragm contains 55\% type I fibers and 45\% type II fibers, almost all of which were classified as IIa. No type IIc fibers were identified. The fiber type distribution was the same in $\mathrm{Di}_{\mathrm{E}}$ and $\mathrm{Di}_{\mathrm{N}}(P$ $\leq 0.4)$. The average cross-sectional area of type I fibers in $\mathrm{Di}_{\mathrm{E}}$ and $\mathrm{Di}_{\mathrm{N}}$ was $1,132 \pm 48$ and $1,191 \pm 68 \mu \mathrm{m}^{2}$, respectively $(P$ $\leq 0.4)$. In 7 of 10 animals, the cross-sectional area of type II fibers of $\mathrm{Di}_{\mathrm{E}}$ was smaller than that of $\mathrm{Di}_{\mathrm{N}}(1,093 \pm 62$ vs. $\left.1,224 \pm 45 \mu \mathrm{m}^{2}\right)$, but this trend did not reach statistical signifcance $(P \leq 0.15)$. The maximal tetanic tensions of $\mathrm{Di}_{\mathrm{E}}$ and $\mathrm{Di}_{\mathrm{N}}$ were the same, i.e., $2.49 \pm 0.14$ and $2.50 \pm 0.15 \mathrm{~kg} / \mathrm{cm}^{2}$ $(P \geq 0.5)$.

Fig. 3 shows the average isometric length-tension plots of $\mathrm{Di}_{\mathrm{E}}$ (broken line through open symbols) and $\mathrm{Di}_{\mathrm{N}}$ (solid line through closed symbols) from 10 animals. There was no significant difference in muscle force between $\mathrm{Di}_{\mathrm{E}}$ and $\mathrm{Di}_{\mathrm{N}}$ at lengths ranging from 50 to $125 \%$ Lo.

In situ regional lengths and their relationships to regional $L o(n=10)$. Fig. 4 shows an identity plot of the resting lengths of $\mathrm{Di}_{\mathrm{E}}$ and $\mathrm{Di}_{\mathrm{N}}\left(\mathrm{Lr}_{\mathrm{E}}, \mathrm{Lr}_{\mathrm{N}}\right)$, each normalized by their respective optimal lengths $\left(\mathrm{Lo}_{\mathrm{E}}, \mathrm{LO}_{\mathrm{N}}\right)$. In 8 of 10 animals, $\mathrm{Lr} / \mathrm{Lo}$ of mid costal fibers of $\mathrm{Di}_{\mathrm{E}}$ was less than that of $\mathrm{Di}_{\mathrm{N}}(P \leq 0.05)$. Group mean $\mathrm{Lr} / \mathrm{Lo}$ of $\mathrm{Di}_{\mathrm{E}}$ was $0.91 \pm 0.02$ and that of $\mathrm{Di}_{\mathrm{N}}$ was $0.98 \pm 0.03$.

In Fig. 5, $\Delta \mathrm{PaO}_{\mathrm{E}}$ and $\Delta \mathrm{PaO}_{\mathrm{N}}$ (same values as shown in Fig. 2, left) have been plotted against the active, tetanic lengths of $\mathrm{Di}_{\mathrm{E}}$ and $\mathrm{Di}_{\mathrm{N}}$. Going from right to left, individual data pairs reflect increasing stimulation frequencies from 10 to $50 \mathrm{~Hz}$. The broken line through open symbols represents the behavior of $\mathrm{Di}_{\mathrm{E}}$ and the solid line through closed symbols that of $\mathrm{Di}_{\mathrm{N}}$. In contrast to the differences in $\mathrm{Lr} / \mathrm{Lo}$ (see Fig. 4), $\mathrm{Di}_{\mathrm{E}}$ and $\mathrm{Di}_{\mathrm{N}}$

Table I. In vitro Diaphragm Measurements

\begin{tabular}{|c|c|c|c|c|c|c|c|c|c|c|c|c|}
\hline \multirow[b]{3}{*}{ Dog } & \multicolumn{6}{|c|}{ Emphysema lung-apposed hemidiaphragm } & \multicolumn{6}{|c|}{ Normal lung-apposed hemidiaphragm } \\
\hline & \multicolumn{3}{|c|}{ Distribution of fiber types } & \multicolumn{2}{|c|}{ Cross-sectional area } & \multirow{2}{*}{$\begin{array}{c}\text { Maximal } \\
\text { force }\end{array}$} & \multicolumn{3}{|c|}{ Distribution of fiber types } & \multicolumn{2}{|c|}{ Cross-sectional area } & \multirow{2}{*}{$\begin{array}{l}\text { Maximal } \\
\text { force }\end{array}$} \\
\hline & I & IIa & IIb & I & II & & I & IIa & IIb & I & II & \\
\hline & \multicolumn{3}{|c|}{$\%$ Total } & \multicolumn{2}{|c|}{$\mu m^{2}$} & $\mathrm{~kg} / \mathrm{cm}^{2}$ & \multicolumn{3}{|c|}{$\%$ Total } & \multicolumn{2}{|c|}{$\mu m^{2}$} & $\mathrm{~kg} / \mathrm{cm}^{2}$ \\
\hline 1 & 68 & 32 & 0 & 1,081 & 979 & 2.47 & 70 & 30 & 0 & 1,464 & 1,133 & 2.54 \\
\hline 2 & 49 & 50 & 1 & 1,186 & 1,040 & 2.22 & 56 & 42 & 2 & 1,567 & 1,480 & 1.29 \\
\hline 3 & 60 & 37 & 3 & 1,021 & 906 & 2.03 & 50 & 47 & 3 & 896 & 970 & 2.36 \\
\hline 4 & 60 & 37 & 3 & 1,206 & 1,132 & 1.57 & 67 & 31 & 2 & 1,271 & 1,193 & 2.61 \\
\hline 5 & 60 & 39 & 1 & 1,235 & 1,246 & 2.63 & 63 & 37 & 0 & 1,301 & 1,382 & 2.15 \\
\hline 6 & 45 & 54 & 1 & 1,231 & 1,225 & 3.13 & 47 & 53 & 0 & 1,175 & 1,153 & 3.06 \\
\hline 7 & 52 & 48 & 0 & 1,056 & 1,049 & 2.86 & 59 & 40 & 1 & 1,157 & 1,279 & 2.62 \\
\hline 8 & 56 & 44 & 0 & 1,374 & 1,368 & 2.79 & 50 & 49 & 1 & 1,020 & 1,191 & 2.66 \\
\hline 9 & 52 & 48 & 0 & 865 & 744 & 2.25 & 52 & 46 & 2 & 1,195 & 1,344 & 2.53 \\
\hline 10 & 50 & 49 & 1 & 1,062 & 1,239 & 2.95 & 49 & 51 & 0 & 868 & 1,110 & 3.15 \\
\hline Mean & 55 & 44 & 1 & 1,132 & 1,093 & 2.49 & 56 & 43 & 1 & 1,191 & 1,224 & 2.50 \\
\hline $\mathrm{SE}$ & 2 & 2 & 0.35 & 48 & 62 & 0.14 & 2 & 2 & 0.33 & 68 & 45 & 0.15 \\
\hline
\end{tabular}




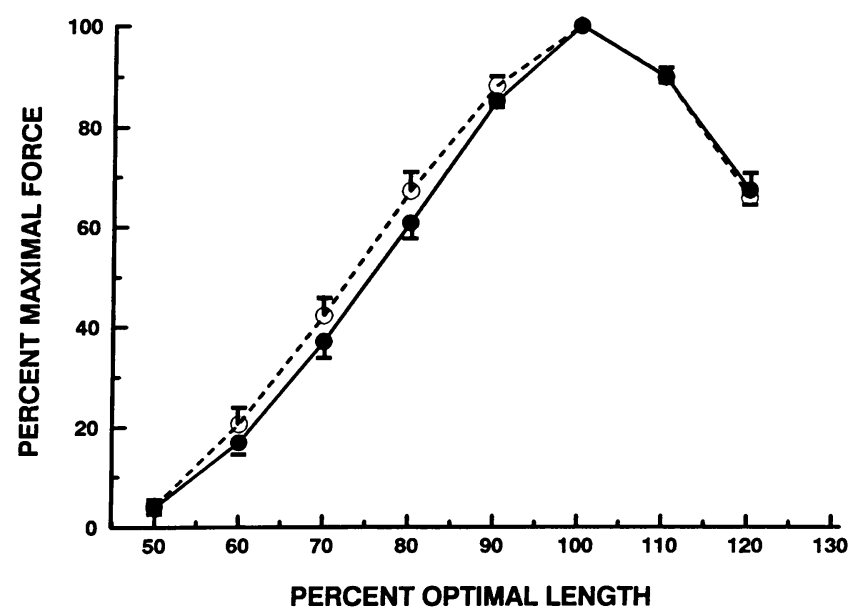

Figure 3. Isometric length-tension relationship in excised muscle strips of $\mathrm{Di}_{\mathrm{E}}$ (broken line, open symbols) and $\mathrm{Di}_{\mathrm{N}}$ (solid line, closed symbols) from 10 dogs.

reached the same active length ( normalized by Lo) during bilateral phrenic nerve stimulations. Therefore, $\mathrm{Di}_{\mathrm{E}}$ shortened less and generated less pressure than $\mathrm{Di}_{\mathrm{N}}$ even though its active length was the same as that of $\mathrm{Di}_{\mathrm{N}}$.

\section{Discussion}

The results of this study show that the deformation of the diaphragm produced by changes in lung size, shape, and mechanical properties has an impact on diaphragm function. We have demonstrated that $\mathrm{Di}_{\mathrm{E}}$ and $\mathrm{Di}_{\mathrm{N}}$ do not share the same capacity for lowering lung surface pressure. When both are recruited equally, they contract to the same active length (relative to

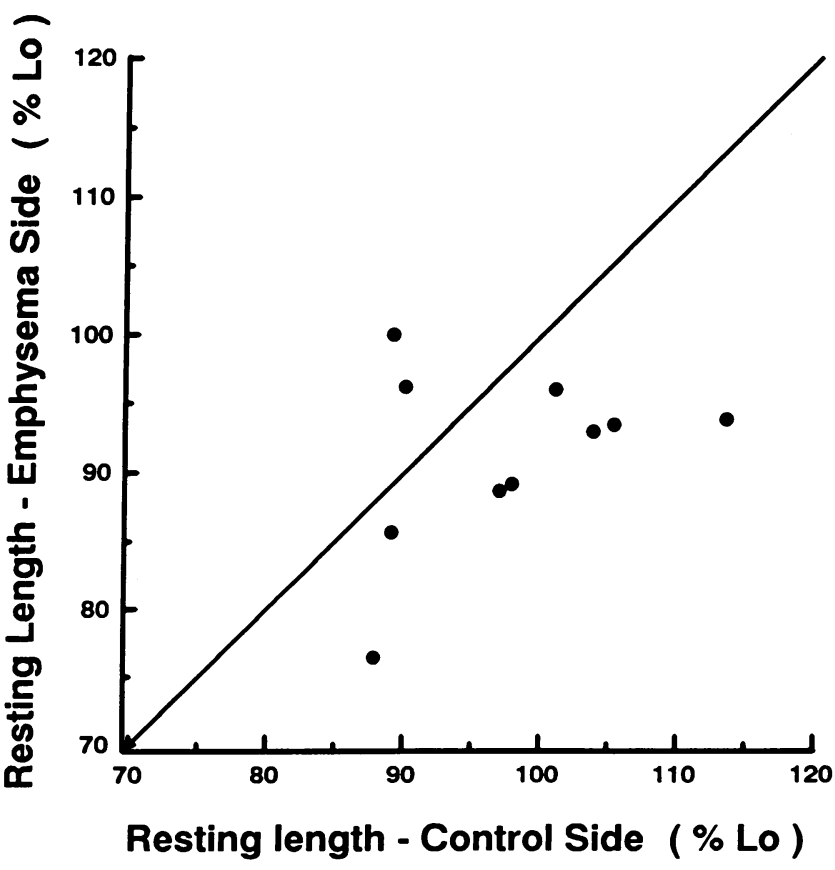

Figure 4. Comparison between $\mathrm{Lr} / \mathrm{Lo}$ of $\mathrm{Di}_{\mathrm{N}}$ (abscissa) and $\mathrm{Di}_{\mathrm{E}}($ ordinate) in 10 dogs.

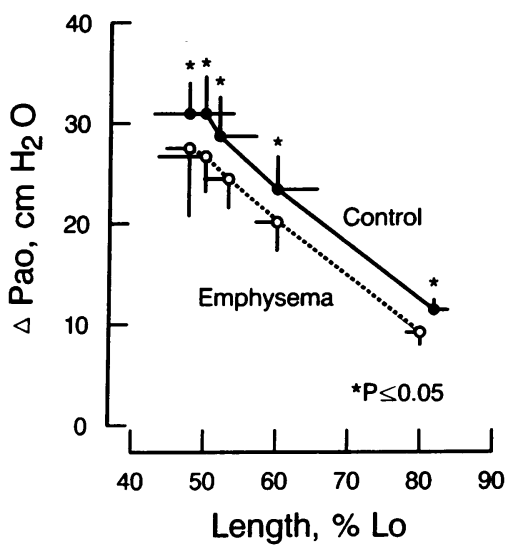

Figure 5. Relationships lengths of $\mathrm{Di}_{\mathrm{E}}$ (broken line through open symbols) and $\mathrm{Di}_{\mathrm{N}}($ solid line through closed symbols) during bilateral phrenic nerve stimulation at $\mathrm{Hz}$ and the corresponding changes in airway occlusion pressures ( $\triangle$ Pao). Regional lengths are expressed as \%Lo. An asterisk indicates a significant difference in $\triangle \mathrm{Pao}$ at comparable length. between the tetanic rates between 10 and 50

Lo), and, given equal intrinsic contractile properties, they produce comparable forces in situ. Therefore, we conclude that the principal mechanism for unequal hemithoracic pressures during phrenic stimulation is a difference in the mechanical efficiency of the hemidiaphragms. In the following sections, we will discuss the rationale behind our experimental approach, review the underlying assumptions and the potential limitations of this study, and, finally, address the clinical and physiological significance of our findings.

Mechanical coupling of the pleural spaces. The principal observation of this study, which motivated us to explore the determinants of regional diaphragm mechanics in dogs with unilateral hyperinflation, was the inequality in lung surface pressure during bilateral phrenic nerve stimulation. Different mean hemithoracic pressures can be sustained only if the lungs and thoracic midline structures resist deformation and displacement. In the absence of chest wall deformation by the respiratory muscles, i.e., during passive deflation of the relaxed respiratory system, mean pleural pressure is equal in the hemithoraces of dogs with unilateral emphysema (2). The dependence of the interpulmonary pleural pressure distribution on chest wall shape suggests that, during phrenic nerve stimulation, the descent of the diaphragm places an axial tension on the mediastinum, thereby reducing its so-called "compliance." It also suggests that the lungs may not be sufficiently deformable to maintain uniform surface pressures when the chest wall shape has been altered by diaphragm activation.

Relationship between diaphragm force output and the change in intrathoracic pressure. The pressure a muscle exerts on the respiratory system is determined by the force it produces and its mechanical advantage in displacing lungs and chest wall. Many of the current working hypotheses concerning respiratory muscle use in humans have been derived from their isometric length-tension properties (11). It is assumed that a muscle that operates near its Lo is better equipped to produce force and perform respiratory work. Since the respiratory muscles shorten as they deform the respiratory system, however, there is no unique relationship between initial length and force output $(12,13)$. Because of the complex interactions between muscle recruitment, muscle contractility, the load against which muscles shorten, and their different mechanical actions on the thorax, the distribution of forces that respiratory muscles produce during breathing is not known. 
To determine if $\mathrm{Di}_{\mathrm{E}}$ and $\mathrm{Di}_{\mathrm{N}}$ produce similar forces in situ, we had to impose conditions that do not occur during breathing per se, but provide insight into how the diaphragm functions when its length and geometry have been altered. This was accomplished (1) by inferring inhomogeneities in intrathoracic pressure from $\Delta \mathrm{PaO}$ and from the amount of Pendelluft that is transferred from emphysematous to the normal lung during phrenic nerve stimulation; ( 2 ) by assuring equal in situ activation of $\mathrm{Di}_{\mathrm{E}}$ and $\mathrm{Di}_{\mathrm{N}} ;$ (3) by measuring the in situ lengths of diaphragm muscle bundles during steady tetanic contractions; (4) by defining microstructure and the intrinsic contractile properties of different diaphragm regions; and (5) by relating in situ tetanic lengths to measurements of isometric muscle tension in vitro.

$\Delta \mathrm{Pao}$ were measured to characterize actions of each hemidiaphragm on the apposing lung. This approach is based on the rationale that $\Delta \mathrm{Pao}$ provides a better estimate of the overall change in lung surface pressure than any one local pressure measurement in the esophagus or pleural space. Differences in $\Delta \mathrm{Pao}$ cannot be attributed to differences in lung compliance. During diaphragm contractions against an occluded airway, the compliance of the lung becomes essentially that of its resident gas. $\Delta$ Pao will be less than the change in mean surface pressure only ( 1 ) if there is a significant increase in volume due to gas rarification and (2) if the lung resists isovolumic deformations. There is no reason to invoke either mechanism as an explanation for the differences in $\Delta \mathrm{Pao}$ between emphysematous and normal lung.

The mechanical efficiency of the diaphragm is defined by the relationship between transdiaphragmatic pressure and diaphragm force. We did not measure changes in transdiaphragmatic pressure, yet have made inferences about the mechanical efficiency of each hemidiaphragm on the basis of lung surface pressure measurements. Our reasoning is valid as long as the change in abdominal pressure near $\mathrm{Di}_{\mathrm{E}}$ does not substantially exceed that near $\mathrm{Di}_{\mathrm{N}}$. Subdiaphragmatic pressure changes in proportion to the local displacement of the diaphragm and to the resistance of the abdominal structures to displacement (14). There is no reason to think that $\mathrm{Di}_{\mathrm{E}}$ undergoes a greater caudal displacement than $\mathrm{Di}_{\mathrm{N}}$ during phrenic stimulation. If anything, unilateral hyperinflation and secondary flattening of the apposing hemidiaphragm should reduce the capacity of $\mathrm{Di}_{\mathrm{E}}$ to descend. The consistency of our observations across animals with right or left emphysema argues against systematic differences in the impedances of abdominal structures near $\mathrm{Di}_{\mathrm{E}}$ and $\mathrm{Di}_{\mathrm{N}}$.

Relationships between active muscle length, pressure, and force generation in situ. The in situ lengths of tetanically contracted muscle bundles of mid costal $\mathrm{Di}_{\mathrm{E}}$ and $\mathrm{Di}_{\mathrm{N}}$ were treated as indirect measures of regional force. This is a valid approach provided (1) the force produced by a tetanically contracted muscle bundle is in equilibrium with the elastic load that opposes fiber shortening; and (2) during a tetanus, the tension along muscle fibers varies only with active length (according to a unitary isometric length-tension relationship) and is independent of precontraction length (i.e., Lr/Lo) and rate of shortening. The first assumption was satisfied by restricting measurements to instances during which in situ regional lengths and Pao had reached a constant value. The validity of the second assumption is supported by work on frog and canine limb muscles $(12,13)$ and on mammalian diaphragm (15). Muscle fibers that are stimulated at different initial lengths but are allowed to shorten to the same, active length produce the same force. The force produced is independent of initial length and amount of shortening provided sufficient time is available to reach a new steady state. The time until the force of the shortened frog muscle reaches a value predicted by the isometric length-tension curve is inversely related to stimulation frequency and is $\leq 1 \mathrm{~s}$ for a $20-\mathrm{Hz}$ tetanus (12). In contrast, the force produced during twitch stimulation is not a unique function of final length but varies with initial length and shortening. Supported by these observations, we have treated tetanic diaphragm lengths as indirect measures of regional muscle tension in situ.

We failed to detect a significant difference in tetanic lengths of mid costal regions of $\mathrm{Di}_{\mathrm{E}}$ and $\mathrm{Di}_{\mathrm{N}}$ at any stimulation rate. Given the similarity in intrinsic contractile properties (Table I), we conclude that mid costal regions of $\mathrm{Di}_{\mathrm{E}}$ and $\mathrm{Di}_{\mathrm{N}}$ produced comparable average forces during bilateral phrenic nerve stimulation. This finding also implies that the loads that opposed muscle shortening during bilateral phrenic nerve stimulation were comparable. Small systematic differences in hemidiaphragm force output may have escaped detection, because there are limits to the resolution of sonomicrometry as a measurement tool of in vivo muscle length $( \pm 0.05 \mathrm{~mm})$ and because both diaphragm regions shortened to near minimum lengths (at which tetanic force approaches 0 ) when the stimulus rate was $\geq 30 \mathrm{~Hz}$. However, we could not detect side-to-side differences in active diaphragm length at lower stimulus rates (and lengths between 60 and $80 \%$ Lo) either (Fig. 5). The similarity in active hemidiaphragm lengths over a wide range of stimulation frequencies suggests that the differences in $\mathrm{PaO}$ primarily reflect differences in the mechanical efficiency of $\mathrm{Di}_{\mathrm{E}}$ and $\mathrm{Di}_{\mathrm{N}}$. Differences in mechanical efficiencies may, in turn, be attributed to differences in hemidiaphragm shape (1).

Diaphragm adaptation to chronic unilateral hyperinflation. The diaphragm, like other skeletal muscles, adapts and remodels in response to altered use (16). We considered the possibilities that chronic unilateral hyperinflation induces nonuniform changes in intrinsic diaphragm length, microstructure, and contractile properties and that these may contribute to systematic differences in the force-generating capacity between $\mathrm{Di}_{\mathrm{E}}$ and $\mathrm{Di}_{\mathrm{N}}$. Our morphometric results and in vitro measures of contractile properties apparently do not support this hypothesis. There are two caveats, however: (1) our analysis was restricted to mid costal diaphragm regions; and (2) conclusions are based on comparisons between $\mathrm{Di}_{\mathrm{E}}$ and $\mathrm{Di}_{\mathrm{N}}$ instead of comparisons between pre- and postemphysema states. In previous studies on mechanically ventilated and spontaneously breathing normal dogs, we found no systematic variability in length and fractional shortening among different costal and crural regions of the diaphragm $(17,18)$. During bilateral phrenic nerve stimulation against an occluded airway, the changes in overall diaphragm length dominated the regional variability in diaphragm function (1). Therefore, we feel confident that our inferences on hemidiaphragm function, which were based on the behavior of a single region, have general validity.

Previous studies in hamsters found no change in the distribution of diaphragm fiber types after bilateral emphysema (19-21). This is consistent with the similarity in fiber type distribution between $\mathrm{Di}_{\mathrm{E}}$ and $\mathrm{Di}_{\mathrm{N}}$ in this study. There is disagreement on the effects of emphysema on diaphragm fiber size in the hamster model. Selective type II fiber hypertrophy (21), type II fiber atrophy (19), and hypertrophy of both type I 
and type II fibers (20) have been described. We found no difference in fiber size between $\mathrm{Di}_{\mathrm{E}}$ and $\mathrm{Di}_{\mathrm{N}}$ in our dogs. It is unclear to what extent differences in species, age, activity, and nutritional status of the animals account for this discrepancy in the literature.

Length adaptation of the diaphragm to chronic hyperinflation has been documented in emphysematous hamsters (19, 20 ). Because of in series sarcomere dropout, the Lo of diaphragm bundles decreased in these animals. It is not known whether length adaptation preserves the relationship between $\mathrm{Lr}$ and Lo, however. We found significant differences in $\mathrm{Lr} / \mathrm{Lo}$ between $\mathrm{Di}_{\mathrm{E}}$ and $\mathrm{Di}_{\mathrm{N}}$, which is inconsistent with perfect regional length adaptation, i.e., sarcomere dropout to the point where maximal force generating capacity at the new operating length $(\mathrm{Lr})$ is preserved. This finding does not preclude the possibility, however, that Lo of both hemidiaphragms had decreased in response to unilateral hyperinflation, albeit by different amounts. Estimates of $\mathrm{Lr} / \mathrm{Lo}$ of the costal diaphragm in normal dogs range from 0.94 to 1.05 (22), which is slightly greater than the $\mathrm{Lr} / \mathrm{Lo}$ of $0.91 \pm 0.02$ we have measured in $\mathrm{Di}_{\mathrm{E}}$ samples. The difference in effective lengths $(\mathrm{Lr} / \mathrm{Lo})$ between $\mathrm{Di}_{\mathrm{E}}$ and $\mathrm{Di}_{\mathrm{N}}$ most likely reflects regional differences in lung volume. Differences between the passive lengths (relative to Lo) of $\mathrm{Di}_{\mathrm{E}}$ and $\mathrm{Di}_{\mathrm{N}}$ were preserved up to a thoracic volume near baseline, preemphysema TLC. Further inflation of the relaxed respiratory system resulted in selective shortening of $\mathrm{Di}_{\mathrm{N}}$, while the length of $\mathrm{Di}_{\mathrm{E}}$ remained constant (Fig. 1). On the basis of direct inspection of $\mathrm{Di}_{\mathrm{E}}$ through a laparotomy, we suspect that $\mathrm{Di}_{\mathrm{E}}$ reaches its unstressed length below the new system TLC and begins to buckle during positive pressure inflation to high volumes.

Possible implications of findings for interpulmonary ventilation distribution after single lung transplantation. There are obvious differences in type and timing between the deformations resulting from experimental emphysema and those resulting from the implantation of a "new" lung. Nevertheless, our findings suggest that the determinants of the interpulmonary ventilation distribution need not be limited to the intrinsic mechanical properties of the lungs (23). The mutual deformations of lungs and chest wall that follow the implantation of a lung with different size and shape could have important consequences on the ability of implant and native lung-apposed hemidiaphragms to lower lung surface pressure.

\section{Acknowledgments}

We thank Mark Schroeder, Lauri Monahan, and Dr. Robert Schriner for their technical assistance and Lori Oeltjenbruns for preparing the manuscript.

Supported by grants HL-43865, HL-37680, and HL-45026 from the National Institutes of Health.

\section{References}

1. Hubmayr, R. D., J. J. Sprung, and S. B. Nelson. 1990. The determinants of transdiaphragmatic pressure in dogs. J. Appl. Physiol. 69:2050-2056.

2. Margulies, S. S., R. W. Schriner, M. A. Schroeder, and R. D. Hubmayr. 1992. Static lung-lung interactions in unilateral emphysema. J. Appl. Physiol. 73:545-551

3. Takaro, T., and S. M. White. 1973. Unilateral severe experimental pulmonary emphysema. Am. Rev. Respir. Dis. 108:334-342.

4. Farkas, G. A., and D. F. Rochester. 1988. Functional characteristics of canine costal and crural diaphragm. J. Appl. Physiol. 65:2427-2433.

5. Newman, S., J. Road, F. Bellemare, J. P. Clozel, C. M. Lavigne, and A. Grassino. 1984. Respiratory muscle length measured by sonomicrometry. $J$. Appl. Physiol. 56:753-764.

6. Close, R. I. 1972. Dynamic properties of mammalian skeletal muscle. Physiol. Rev. 52:129-197.

7. Sieck, G. C., R. D. Sacks, and C. E. Blanco. 1987. Absence of regional differences in the size and oxidative capacity of diaphragm muscle fibers. J. Appl. Physiol. 63:1076-1082.

8. Sieck, G. C., R. D. Sacks, C. D. Blanco, and V. R. Edgerton. 1986. SDH activity and cross-sectional area of muscle fibers in cat diaphragm. J. Appl. Physiol. 60:1284-1292.

9. Brooke, M. H., E. Williamson, and K. K. Kaiser. 1971. The behavior of 4 fiber types in developing and reinervated muscle. Arch. Neurol. 25:360-366.

10. Sieck, G. C., T. S. Cheung, and C. E. Blanco. 1991. Diaphragm capillarity and oxidative capacity during postnatal development. J. Appl. Physiol. 70:103111.

11. Hagan, B. M., and R. D. Hubmayr. 1991. Respiratory failure: dynamics of breathing and coordination. In Update in Intensive Care and Emergency Medicine. Ventilatory Failure. Vol. 15. J.-L. Vincent, editor. Springer Verlag New York Inc., New York. 75-96.

12. Edman, K. A. P. 1981. Deactivation of the contractile system induced by shortening of striated muscle. In The Regulation of Muscle Contraction. A. D. Ginnell, editor. Academic Press Inc., San Diego, CA. 281-296.

13. Joyce, G. C., P. M. H. Rack, and D. R. Westbury. 1969. The mechanical properties of cat soleus muscle during controlled lengthening and shortening movements. J. Physiol. (Lond.). 204:461-474.

14. Decramer, M., A. DeTroyer, S. Kelly, L. Zocchi, and P. T. Macklem. 1984. Regional differences in abdominal pressure swings in dogs. J. Appl. Physiol. 57:1682-1687.

15. Mardini, I. A., and R. J. McCarter. 1987. Contractile properties of the shortening rat diaphragm in vitro. J. Appl. Physiol. 62:1111-1116.

16. Saltin, B., and P. D. Gollnick. 1983. Skeletal muscle adaptability: significance for metabolism and performance. In Handbook of Physiology. Skeletal Muscle. Section 10, Chapter 19. L. D. Peachy, R. H. Adrian, and S. R. Geiger, editors. Williams \& Wilkins, Baltimore, MD. 555-631.

17. Sprung, J., C. Deschamps, R. D. Hubmayr, B. J. Walters, and J. R. Rodarte. 1989. In vivo regional diaphragm function in dogs. J. Appl. Physiol. 67:655-662.

18. Sprung, J., C. Deschamps, S. S. Margulies, R. D. Hubmayr, and J. R. Rodarte. 1990. Effect of body position on regional diaphragm function. J. Appl. Physiol. 69:2296-2302.

19. Farkas, G. A., and C. Roussos. 1982. Adaptability of the hamster diaphragm to exercise and/or emphysema. J. Appl. Physiol. 53:1263-1272.

20. Kelsen, S. G., T. Wolanski, G. S. Supinski, and U. Roessmann. 1983. The effect of elastase-induced emphysema on diaphragmatic muscle structure in hamsters. Am. Rev. Respir. Dis. 127:330-334.

21. Lewis, M. I., W. Z. Zhan, and G. C. Sieck. 1992. Adaptation of the diaphragm in emphysema. J. Appl. Physiol. 72:934-943.

22. Margulies, S. S., G. A. Farkas, and J. R. Rodarte. 1990. Effects of body position and lung volume on in situ operating length of canine diaphragm. $J$. Appl. Physiol. 69:1702-1708.

23. Hubmayr, R. D., S. S. Margulies, and B. J. Walters. 1992. Interpulmonary ventilation distribution in dogs with unilateral emphysema. FASEB (Fed. Am. Soc. Exp. Biol.) J. 6:A1513 (Abstr.). 